\title{
Effect of Angelica gigas extract on melanogenesis in B16 melanoma cells
}

\author{
NA LV ${ }^{1 *}$, JEUNG-HYUN KOO ${ }^{*}$, HA-YONG YOON ${ }^{1}$, JIAHUA YU ${ }^{1}$, KYUNG-AH KIM ${ }^{1}$, IL-WHAN CHOI ${ }^{2}$, \\ KANG-BEOM KWON ${ }^{3}$, KEUN-SANG KWON ${ }^{4}$, HAN-UK KIM $^{5}$, JIN-WOO PARK ${ }^{1}$ and BYUNG-HYUN PARK ${ }^{1}$ \\ ${ }^{1}$ Department of Biochemistry, Medical School and Institute for Medical Sciences, Chonbuk National University, \\ Jeonju, Jeonbuk 561-756; ${ }^{2}$ Department of Microbiology, College of Medicine, Inje University, Busan 614-735; \\ ${ }^{3}$ Department of Physiology, School of Oriental Medicine, Wonkwang University, Iksan, Jeonbuk 570-749; \\ Departments of ${ }^{4}$ Preventive Medicine, ${ }^{5}$ Dermatology, Medical School and Institute for Medical Sciences, \\ Chonbuk National University, Jeonju, Jeonbuk 561-756, Korea
}

Received July 16,2007; Accepted August 27, 2007

\begin{abstract}
During the screening of herbs for inhibition of melanogenesis, it was observed that ethanolic extract of Angelicae Gigantis Radix (AGE) effectively inhibited isobutylmethylxanthine-induced melanogenesis in B16 melanoma cells. The melanin content was significantly decreased by AGE in a dose-dependent manner, and no cytotoxicity was observed at the effective concentrations. Decreased melanin content was accompanied by reduced enzyme activity as well as reduced expression of tyrosinase protein and mRNA. The level of tyrosinase-related protein 1 and 2 mRNAs was also decreased by AGE. Additionally, AGE effectively inhibited $\alpha$-melanocyte stimulating hormoneand forskolin-induced melanogenesis, and downregulated the mRNA expression of microphthalmia-associated transcription factor, a master transcriptional regulator of melanogenic genes. These results suggest that AGE acts as a putative hypopigmenting agent through downregulation of tyrosinase expression induced via a cAMP-dependent pathway.
\end{abstract}

\section{Introduction}

The unique distribution of pigments throughout the body results in different colors and patterns in all organisms. Pigmentation is highly heritable and is regulated by genetic, environmental, and endocrine factors that modulate the amount, type, and distribution of melanin (1). Melanin is a

Correspondence to: Dr Byung-Hyun Park, Department of Biochemistry, Medical School and Institute for Medical Sciences, Chonbuk National University, Medical School, Jeonju, Jeonbuk 561-756, Korea

E-mail: bhpark@chonbuk.ac.kr

${ }^{*}$ Contributed equally

Key words: Angelica gigas extract, melanogenesis, tyrosinase, cAMP, microphthalmia-associated transcription factor unique pigmented biopolymer that is synthesized by specialized cells known as melanocytes, dendritic cells that comprise a relatively minor portion of the cells present in the dermal-epidermal border of the skin. In addition to its role in the determination of phenotypic appearance and protective coloration, melanin is involved in a number of important functions, such as balance and auditory processing, absorption of toxic drugs and chemicals, and neurologic development during embryogenesis (2). Melanogenesis itself is a complex process, and more than 100 genetic loci are known to regulate mammalian pigmentation either directly or indirectly (3). Mutations of these genes are known to be associated with different pigmentary diseases, including various forms of ocular and oculocutaneous albinism, piebaldism, Hirschsprung's disease, and Waardenberg's syndrome (4).

The tyrosinase gene family is known to play an important role in the regulation of melanogenesis (5). The tyrosinase gene family consists of tyrosinase, tyrosinase-related protein 1 (TRP-1), and tyrosinase-related protein 2 (TRP-2) (4). Tyrosinase is a bifunctional enzyme that plays a pivotal role in the modulation of melanin production by catalyzing the hydroxylation of tyrosine to 3,4-dihydroxy-phenylalanine (DOPA) and the oxidation of DOPA to DOPAquinone (6). TRP-2, which functions as a DOPAchrome tautomerase, catalyzes the rearrangement of DOPAchrome to 5,6-dihydroxy-indole-2-carboxylic acid (DHICA) (7), whereas TRP-1 oxidizes DHICA to a carboxylated indole-quinone (8). Microphthalmia-associated transcription factor (MITF) is known to be a master regulator of melanocyte development and melanogenesis (9) that regulates the transcription of three major pigmentation enzymes: tyrosinase, TRP-1 and TRP-2. The promoters of these genes contain the MITF consensus E-box sequence and are expressed in melanocytes.

$\alpha$-melanocyte stimulating hormone $(\alpha-\mathrm{MSH})$ and adrenocorticotropic hormone (ACTH) are involved in the regulation of melanogenesis and melanocyte dentrite formation. It is known that after exposure to UV radiation, $\alpha-\mathrm{MSH}$ and ACTH are produced and released by epidermal keratinocytes (10). After being released, $\alpha-\mathrm{MSH}$ binds to a melanocyte- 
specific receptor, MC1-R (11), which activates adenylate cyclase through $\mathrm{G}$ protein. cAMP is then elevated from ATP by adenylate cyclase (1), and exerts its effect, in part, through protein kinase A (PKA) (12). Inhibitors of melanin synthesis have been the focus of many studies because they are related to localized hyperpigmentation in humans, such as melasma, lentigines, nevus, ephelis, and post-inflammatory state.

Angelica gigas, which is known as 'Korean danggui', belongs to the Umbelliferae family, which also includes Angelica sinensis (Chinese danggui) and Angelica acutiloba (Japanese danggui). They have been used to treat women with gynecological diseases and anemia because of their hematopoietic, analgesic and sedative activities $(13,14)$. Other pharmacologic effects including antibacterial (15), immunostimulating (16), antitumor (17), neuroprotective (18), antinociceptive (19) and anti-amnestic (20) activities, have been reported. During the screening of herbs for the inhibition of melanogenesis, we observed that ethanolic extract of Angelicae Gigantis Radix (AGE) effectively inhibited isobutylmethylxanthine (IBMX)-induced melanogenesis in B16 melanoma cells. AGE may act as a putative hypopigmenting agent through downregulation of tyrosinase expression induced via a cAMP-dependent pathway.

\section{Materials and methods}

Cell culture and materials. The B16/F10 murine melanoma cell line was obtained from the Korean Cell Line Bank (Seoul, Korea). Cells were cultured in DMEM containing $10 \%$ fetal bovine serum, $100 \mathrm{U} / \mathrm{ml}$ penicillin, $0.1 \mathrm{mg} / \mathrm{ml}$ streptomycin and $0.25 \mu \mathrm{g} / \mathrm{ml}$ amphotericin $\mathrm{B}$ at $37^{\circ} \mathrm{C}$ in a humidified atmosphere comprised of $95 \%$ air and $5 \% \mathrm{CO}_{2}$, as described previously (21). Ethanolic extract of Angelicae Gigantis Radix (CA01-030) was obtained from the Korean Plant Extract Bank (Daejeon, Korea), and $\alpha$-MSH, 3-isobutyl1-methylxanthine (IBMX) and forskolin were obtained from Sigma Chemical Co. (St. Louis, MO, USA). Drug treatment began $24 \mathrm{~h}$ after the cells were seeded, and cells were harvested after 2 days of incubation.

Measurement of melanin content. The melanin content of the cultured B16 cells was measured as described previously (22). Briefly, the cells were washed twice with phosphatebuffered saline (PBS) and then lysed with $20 \mathrm{mM}$ Tris- $0.1 \%$ Triton X-100 ( $\mathrm{pH} 7.5)$. Cell lysates were precipitated using the same amount of $20 \%$ trichloroacetic acid (TCA). After washing twice with $10 \%$ TCA, the pellets were treated with ethyl alcohol:diethyl ether (3:1) and diethyl ether successively. Samples were air-dried, dissolved in $1 \mathrm{ml}$ of $0.85 \mathrm{M} \mathrm{KOH}$, and boiled for $15 \mathrm{~min}$. After cooling, the absorbance at $440 \mathrm{~nm}$ was measured using a spectrophotometer. The amount of cellular melanin was corrected based on the DNA content of the sample, which was determined by a fluorescence assay with bisbenzimide H 33258 (23) using a DNA quantitation kit (Sigma).

Tyrosinase activity assay. Tyrosinase activity was assayed as DOPA oxidase activity using the method described by Lerch, with slight modifications (24). Briefly, cell lysates were obtained after washing twice with PBS. Tyrosinase activity was analyzed spectrophotometrically by following the oxidation of DOPA to DOPAchrome at $475 \mathrm{~nm}$. A reaction mixture containing $100 \mu 1$ of freshly prepared substrate solution $(0.1 \%$ L-DOPA in $0.1 \mathrm{M}$ sodium phosphate, $\mathrm{pH}$ 6.0) and $50 \mu 1$ of enzyme solution was incubated at $37^{\circ} \mathrm{C}$, and the change in absorbance was measured during the first $10 \mathrm{~min}$ of the reaction, during which time a linear increase in absorbance occurred. The tyrosinase activity was corrected based on the DNA content of the samples, and was then presented as a percentage of the IBMX-treated control cells.

MTT assay. The viability of cultured cells was determined by reduction of 3-(4,5-dimethylthiazol-2-yl)-2,5-diphenyltetrazolium bromide (MTT) (Sigma) to formazan as described previously (25). Cells were seeded in 96 wells and then cultured for $24 \mathrm{~h}$. After drug treatment, MTT $(5 \mathrm{mg} / \mathrm{ml}$ in PBS, $100 \mu \mathrm{l}$ ) was added to each well. Cells were then incubated at $37^{\circ} \mathrm{C}$ for $30 \mathrm{~min}$, followed by addition of dimethyl sulfoxide (100 $\mu \mathrm{l})$ to dissolve the formazan crystals. The absorbance at $570 \mathrm{~nm}$ was measured using a spectrophotometer (Spectra MAX PLUS, Molecular Devices, Sunnyvale, CA, USA).

Western blotting. Cells were homogenized in ice-cold lysis buffer. The homogenates, which contained $10 \mu \mathrm{g}$ of protein, were separated by SDS-PAGE using a $10 \%$ resolving and $3 \%$ acrylamide stacking gel (26), and then transferred to nitrocellulose membrane (Millipore, Billerica, MA, USA) in a Western blot apparatus (Bio-Rad, Hercules, CA, USA) that was run at $100 \mathrm{~V}$ for $1.5 \mathrm{~h}$. The nitrocellulose membrane was blocked with $2 \%$ bovine serum albumin (Sigma), and incubated overnight with $1 \mu \mathrm{g} / \mathrm{ml}$ goat anti-murine tyrosinase IgG (Santa Cruz Biotechnology Inc., Santa Cruz, CA, USA). The binding of the antibody was detected using anti-goat IgG conjugated with horseradish peroxidase (Sigma). Immunoblots were developed using an Enhanced Chemiluminescence Plus kit (Amersham Biosciences, Buckinghamshire, $\mathrm{UK})$.

Reverse transcription-polymerase chain reaction ( $R T-P C R)$. Total cellular RNA was prepared using Trizol solution (Invitrogen, Paisley, UK) according to the manufacturer's instructions. After preparation of cDNA from the extracted RNA using oligo $d(T)^{16}$ as a reverse transcriptase primer, amplification by PCR was performed using a GeneAmp kit (Perkin EImer, Foster City, CA, USA) according to the manufacturer's instructions. The oligonucleotide primers used for PCR were as follows: tyrosinase upstream 5'-CAT TTT TGA TTT GAG TGT CT-3', downstream 5'-TGT GGT AGT CGT CTT TGT CC-3'; TRP-1 upstream 5'-GCT GCA GGA GCC TTC TTT CTC-3', downstream 5'-AAG ACG CTG CAC TGC TGG TCT-3'; TRP-2 upstream 5'-GGA TGA CCG TGA GCA ATG GCC-3', downstream 5'-CGG TTG TGA CCA ATG GGT GCC-3'; MITF upstream 5'-GTA TGA ACA CGC ACT CTC TCG A-3', downstream 5'-CTT CTG CGC TCA TAC TGC TC-3'; and B-actin upstream 5'-ACC GTG AAA AGA TGA CCC AG-3', downstream 5'-TAC GGA TGT CAA CGT CAC AC-3'. cDNA amplification was conducted on $\sim 1 \mu \mathrm{g}$ of the total RNA obtained from the samples. The reaction was cycled 28 times (for tyrosinase), 
(A)

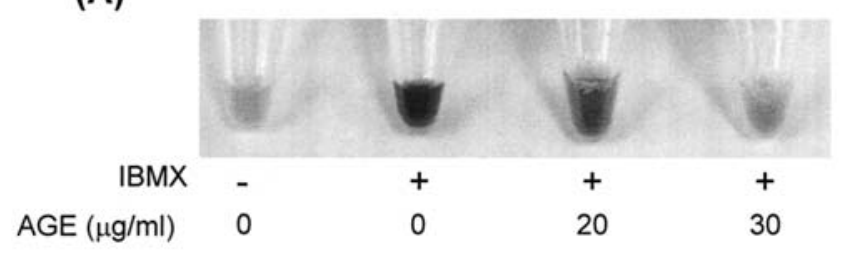

(B)

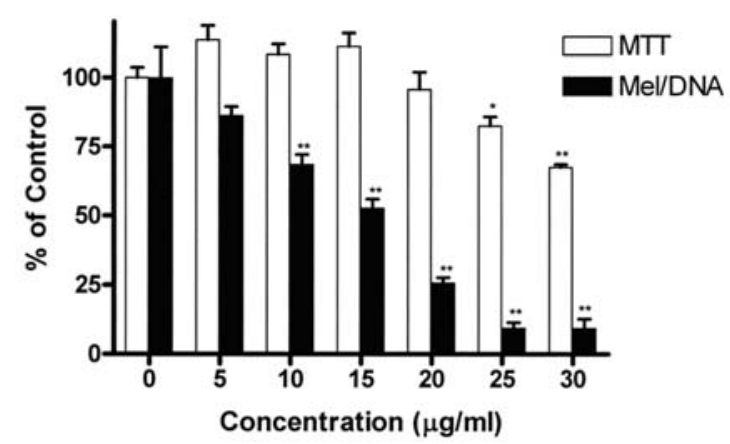

Figure 1. Effect of AGE on melanin content and cytotoxicity in B16 melanoma cells. (A) Cells $\left(5 \times 10^{6} /\right.$ well $)$ were preincubated with $0.1 \mathrm{mM}$ IBMX for $6 \mathrm{~h}$, and then treated with various concentrations of AGE in the presence of IBMX for 2 days. (B) Melanin (Mel) and DNA content was determined as described in Materials and methods. Cell viability was determined by an MTT assay. Data are expressed as a percentage of the control and presented as the mean \pm SEM of three separate experiments. ${ }^{*} \mathrm{P}<0.05$ and ${ }^{* *} \mathrm{P}<0.01$ vs. control.

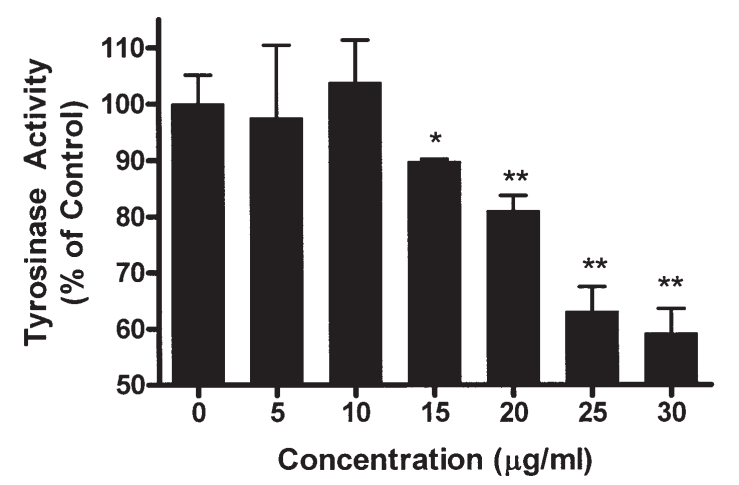

Figure 2. Effect of various concentrations of AGE on cellular tyrosinase activity. Cells $\left(5 \times 10^{6}\right)$ were preincubated with $0.1 \mathrm{mM}$ IBMX for $6 \mathrm{~h}$, and then treated with various concentrations of AGE in the presence of IBMX for 2 days. Tyrosinase activity from cellular lysate was determined as described in Materials and methods. Data are expressed as a percentage of the control and presented as the mean \pm SEM of three separate experiments. ${ }^{*} \mathrm{P}<0.05$ and ${ }^{* *} \mathrm{P}<0.01$ vs. control.

25 (for TRP-1 and -2) and 32 times (for MITF) for $60 \mathrm{sec}$ at $94^{\circ} \mathrm{C}, 60 \mathrm{sec}$ at $56^{\circ} \mathrm{C}$ and $60 \mathrm{sec}$ at $72^{\circ} \mathrm{C}$. Fifty percent of the reaction mixture was then analyzed by electrophoresis on $1 \%$ agarose gels and stained with ethidium bromide.

Statistical analysis. Values were expressed as the mean \pm SEM. The statistical significance of all data was evaluated using the Student's t-test and one-way ANOVA followed by Duncan's test. Differences of $\mathrm{P}<0.05$ were considered statistically significant.
(A)

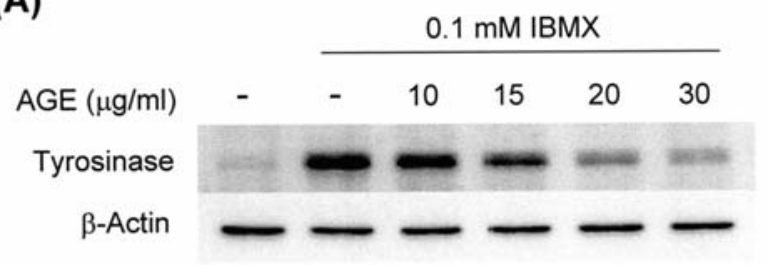

(B)

AGE

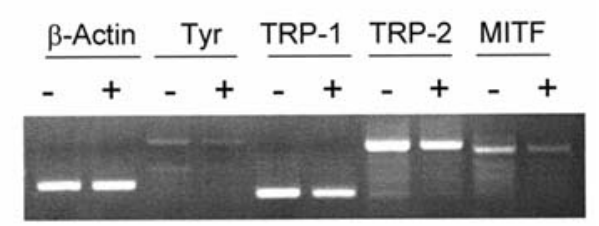

Figure 3. Effect of AGE on tyrosinase protein (A) and mRNA (B) expression. Cells $\left(5 \times 10^{6}\right)$ were treated with a range of concentrations $(10-30 \mu \mathrm{g} / \mathrm{ml})$ of AGE in the presence or absence of $0.1 \mathrm{mM}$ IBMX for 2 days. (A) Tyrosinase protein was analyzed by Western blotting as described in Materials and methods. Experiments were performed three times with similar results, and typical data are presented. (B) Cells $\left(5 \times 10^{6}\right)$ were treated with $0.1 \mathrm{mM}$ IBMX for 2 days in the presence or absence of $20 \mu \mathrm{g} / \mathrm{ml} \mathrm{AGE.} \mathrm{mRNA}$ expression was then visualized by RT-PCR as described in Materials and methods. The sizes of the amplified gene products were 528 bp for actin, 1192 bp for tyrosinase, 268 bp for TRP-1, 1044 bp for TRP-2 and 910 bp for MITF. Tyr, tyrosinase

\section{Results}

When B16 cells were incubated with IBMX, an inhibitor of phosphodiesterase (27), the cell suspension was visibly black, indicating increased cellular melanogenesis (Fig. 1A). To investigate the effect of AGE on IBMX-induced melanogenesis, B16 cells were pretreated with $0.1 \mathrm{mM}$ IBMX for $6 \mathrm{~h}$. Incubation was then continued for 2 days in the presence of both IBMX and various concentrations of AGE. As shown in Fig. 1A, the intensity of the black color of the cell suspension was greatly decreased by the presence of AGE. Cellular melanin content was decreased by AGE in a dose-dependent manner, and a significant decrease in cellular melanin content was observed from an AGE concentration of

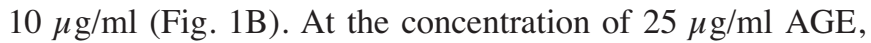
cellular melanin content was decreased to $9.44 \pm 2.0 \%$ of IBMX-treated cells, however an MTT assay showed that $82.4 \pm 3.4 \%$ of the cells were still viable.

Because tyrosinase is the rate-limiting enzyme for melanin biosynthesis, the effect of AGE on tyrosinase activity was determined. Cellular tyrosinase activity was decreased by AGE in a dose-dependent manner (Fig. 2). However, the presence of AGE in the reaction mixture did not affect the tyrosinase activity level, indicating that the decrease in tyrosinase activity by AGE was not due to the direct inhibition of enzyme activity (data not shown). The expression of tyrosinase protein was determined by Western blotting. As shown in Fig. 3A, tyrosinase protein was greatly increased by IBMX treatment, and the IBMX-induced increase in tyrosinase protein expression was significantly inhibited by AGE in a dose-dependent manner. AGE also resulted in a significant decrease in the expression of tyrosinase mRNA 
(A)

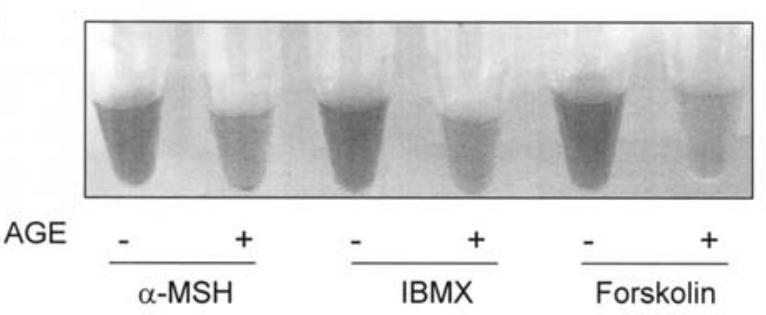

(B)

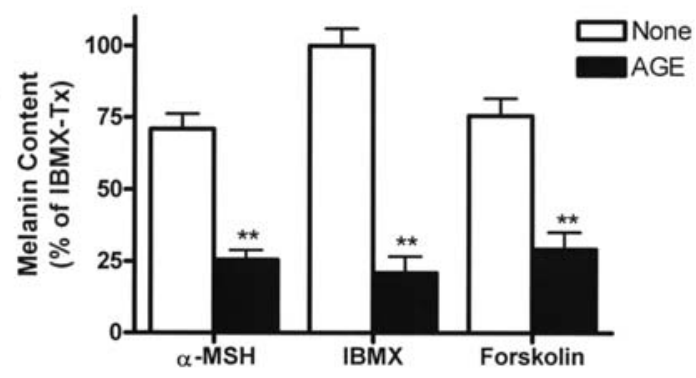

Figure 4. Effect of AGE on $\alpha-M S H-$, IBMX- and forskolin-induced melanogenesis. (A) Cells $\left(5 \times 10^{6}\right)$ were preincubated with IBMX $(0.1 \mathrm{mM})$, $\alpha$-MSH $(5 \mu \mathrm{M})$ or forskolin $(5 \mu \mathrm{M})$ for $6 \mathrm{~h}$, and then treated with $20 \mu \mathrm{g} / \mathrm{ml}$ AGE in the presence of each drug for 2 days. (B) Melanin and DNA content was determined as described in Materials and methods. Data are expressed as a percentage of IBMX-treated cells and presented as the mean \pm SEM of three separate experiments. ${ }^{* *} \mathrm{P}<0.01$ vs. each drug control.

visualized by RT-PCR (Fig. 3B). These results indicate that the inhibition of tyrosinase by AGE was exerted at the transcriptional level. The mRNA expression of TRP-1 and TRP-2, members of the tyrosinase gene family, was also decreased by AGE (Fig. 3B).

The cellular melanin contents were significantly increased in cells that were treated with $5 \mu \mathrm{M} \alpha$-MSH and $5 \mu \mathrm{M}$ forskolin (Fig. 4). $\alpha$-MSH produced by keratinocyte is known to increase adenylate cyclase activity of melanocyte through G protein (12), and it has been reported that forskolin is a direct activator of adenylate cyclase (28). The presence of AGE significantly inhibited the melanogenesis induced by both $\alpha$-MSH and forskolin (Fig. 4), suggesting that AGE regulates gene expression of tyrosinase through a cAMPdependent pathway. PKA that was activated as a result of increased cAMP induced the expression of MITF, a master transcriptional regulator for melanogenic enzymes (9). Therefore, the effect of AGE on the expression of MITF mRNA was investigated by RT-PCR. As shown in Fig. 3B, the presence of AGE significantly decreased the expression of MITF mRNA, suggesting that AGE exerted its inhibitory effect by downregulating MITF transcription.

\section{Discussion}

Among the Angelica species, coumarin derivatives extracted from Angelica dahurica have been reported to stimulate (29) or inhibit melanogenesis (30). In the case of Angelica sinensis, melanogenesis was stimulated (31). However, to our knowledge there have been no reports regarding the effect of
AGE on melanogenesis. In this study, we present evidence that AGE inhibited IBMX-induced melanogenesis in B16 cells.

The melanocyte-keratinocyte complex of the skin responds quickly to a wide range of environmental stimuli, often in paracrine and/or autocrine manners. Exposure of skin to UV radiation results in increased pigmentation, which occurs in two stages; an immediate darkening and a delayed tanning reaction. Immediate pigment darkening is thought to result from oxidation of pre-existing melanin and redistribution of melanosomes. Conversely, the delayed tanning response, which is photoprotective against subsequent UV injury, begins as the immediate pigmentation reaction fades, and continues for at least 3-5 days after UV exposure (32). Delayed tanning is associated with a parallel increase in melanocyte tyrosinase activity $(1,32)$. In B16 cells treated with IBMX, greatly increased melanogenesis was accompanied by increasing tyrosinase activity, protein and mRNA expression, which is similar to the delayed tanning response that occurs after UV irradiation.

IBMX is known to increase cellular cAMP through the inhibition of the cAMP-degrading enzyme, phosphodiesterase (27). IBMX-induced increase in melanogenesis was effectively blocked by AGE at the transcriptional level of tyrosinase. When B16 cells were treated with $\alpha$-MSH (10) or forskolin, an activator of adenylate cyclase (28), cellular melanin contents were significantly increased, however, the presence of AGE significantly inhibited these increases, which are similar to the results observed with IBMX stimulation. These results indicate that the mechanism of AGE occurs via a cAMP-dependent pathway. In addition to the cAMP/PKA pathway, increased melanogenesis after UV irradiation is thought to occur through activation of the diacylglycerol/protein kinase $\mathrm{C}$ (PKC), nitric oxide/protein kinase G (PKG) pathway, or SOS response to UV-induced DNA damage (1). PKG is also known to increase the expression of tyrosinase protein (33). However, PKC-induced activation of tyrosinase occurs through phosphorylation rather than synthesis of the new enzyme (34), which indicates that the controversial stimulatory effect of other Angelica species on melanogenesis $(29,31)$ may be related to the activation of PKC or PKG rather than the cAMP/PKA pathway.

MITF is a tissue restricted, basic helix-loop-helix leucine zipper, dimeric transcription factor. It is encoded by the Mitf locus in mice and, when mutated, leads to defects in melanocytes, the retinal pigmented epithelium, mast cells and osteoclasts. (9). In humans, mutations affecting the MITF pathway lead to pigmentary and auditory defects that are known collectively as Waardenburg's syndrome. (3). When PKA is activated by various stimuli in melanocytes, it activates the cAMP response element binding protein, which binds to the cAMP response element present in the M promoter of the MITF gene $(9,35)$. The increase in MITF-M expression then induces up-regulation of the tyrosinase gene family, which leads to increased melanin synthesis $(9,12)$. The presence of AGE significantly decreased the expression of MITF mRNA, suggesting that AGE exerted its inhibitory effect through the downregulation of MITF transcription. Suppression of MITF mRNA was followed by decreased levels of tyrosinase and TRP-1 and -2 mRNAs. 
Elucidating the molecular mechanisms underlying hyperpigmentation induced by internal or external factors could lead to technology that allows unwanted pigmentation to be decreased and photoaging to be preserved, as well as the design of tanning products with the potential to reduce the risk of skin cancer. The accumulation of melanin in specific parts of the skin as more pigmented patches (melasma, freckles, ephelide, senile lentigines etc.) develop may become an aesthetic problem (36), and chemical compounds that can reduce pigmentation have been used in dermatology and the cosmetics industry $(36,37)$. In this study, we presented evidence that AGE can inhibit IBMX-induced melanogenesis by inhibiting tyrosinase and related enzyme expression at the transcriptional level in B16 cells. This suppressive action occurred through the inhibition of MITF expression, which is a key regulatory transcription factor in melanogenesis. Overall, these results suggest that AGE is a putative hypopigmenting agent.

\section{Acknowledgements}

This study was supported by the Regional Research Centers Program of the Korean Ministry of Education and Human Resources Development through the Center for Healthcare Technology Development and partly by Chonbuk National University (to I. W. Choi).

\section{References}

1. Costin GE and Hearing VJ: Human skin pigmentation: melanocytes modulate skin color in response to stress. FASEB J 21: 976-994, 2007.

2. Hearing VJ: Regulation of melanin formation. In: The Pigmentary System: Physiology and Pathophysiology. Nordlund JJ, Boissy RE, Hearing VJ, King RA and Ortonne J-P (eds). Oxford University Press, Inc., New York, pp423-438, 1998.

3. Lin JY and Fisher DE: Melanocyte biology and skin pigmentation. Nature 445: 843-850, 2007.

4. Hearing VJ: Biochemical control of melanogenesis and melanosomal organization. J Investig Dermatol Symp Proc 4: 24-28, 1999.

5. Pawelek JM and Chakraborty AK: The enzymology of melanogenesis. In: The Pigmentary System: Physiology and Pathophysiology. Nordlund JJ, Boissy RE, Hearing VJ, King RA and Ortonne J-P (eds). Oxford University Press, Inc., New York, pp391-400, 1998.

6. Hearing VJ and Jimenez M: Mammalian tyrosinase - the critical regulatory control point in melanocyte pigmentation. Int $\mathbf{J}$ Biochem 19: 1141-1147, 1987.

7. Yokoyama K, Yasumoto K, Suzuki H and Shibahara S: Cloning of the human DOPAchrome tautomerase/tyrosinase-related protein 2 gene and identification of two regulatory regions required for its pigment cell-specific expression. J Biol Chem 269: 27080-27087, 1994.

8. Kobayashi T, Urabe K, Winder A, et al: Tyrosinase related protein 1 (TRP1) functions as a DHICA oxidase in melanin biosynthesis. EMBO J 13: 5818-5825, 1994.

9. Levy C, Khaled M and Fisher DE: MITF: master regulator of melanocyte development and melanoma oncogene. Trends Mol Med 12: 406-414, 2006.

10. Wakamatsu K, Graham A, Cook D and Thody AJ: Characterisation of ACTH peptides in human skin and their activation of the melanocortin-1 receptor. Pigment Cell Res 10: 288-297, 1997.

11. Cone RD, Lu D, Koppula S, et al: The melanocortin receptors: agonists, antagonists, and the hormonal control of pigmentation. Recent Prog Horm Res 51: 287-317, 1996.

12. Busca R and Ballotti R: Cyclic AMP a key messenger in the regulation of skin pigmentation. Pigment Cell Res 13: 60-69, 2000.
13. Kim MR, El-Aty AM, Choi JH, Lee KB and Shim JH: Identification of volatile components in Angelica species using supercritical- $\mathrm{CO}_{2}$ fluid extraction and solid phase microextraction coupled to gas chromatography-mass spectrometry. Biomed Chromatogr 20: 1267-1273, 2006.

14. Sarker SD and Nahar L: Natural medicine: the genus Angelica. Curr Med Chem 11: 1479-1500, 2004.

15. Lee S, Shin DS, Kim JS, Oh KB and Kang SS: Antibacterial coumarins from Angelica gigas roots. Arch Pharm Res 26: 449-452, 2003.

16. Han SB, Kim YH, Lee CW, et al: Characteristic immunostimulation by angelan isolated from Angelica gigas Nakai. Immunopharmacology 40: 39-48, 1998.

17. Lee S, Lee YS, Jung SH, Shin KH, Kim BK and Kang SS: Antitumor activities of decursinol angelate and decursin from Angelica gigas. Arch Pharm Res 26: 727-730, 2003.

18. Kang SY, Lee KY, Sung SH and Kim YC: Four new neuroprotective dihydropyranocoumarins from Angelica gigas. J Nat Prod 68: 56-59, 2005.

19. Choi SS, Han KJ, Lee HK, Han EJ and Suh HW: Antinociceptive profiles of crude extract from roots of Angelica gigas NAKAI in various pain models. Biol Pharm Bull 26: 1283-1288, 2003.

20. Kang SY, Lee KY, Park MJ, et al: Decursin from Angelica gigas mitigates amnesia induced by scopolamine in mice. Neurobiol Learn Mem 79: 11-18, 2003.

21. Jung GD, Yang JY, Song ES and Park JW: Stimulation of melanogenesis by glycyrrhizin in B16 melanoma cells. Exp Mol Med 33: 131-135, 2001.

22. Yang JY, Koo JH, Song YG, et al: Stimulation of melanogenesis by scoparone in B16 melanoma cells. Acta Pharmacol Sin 27: 1467-1473, 2006.

23. Labarca $\mathrm{C}$ and Paigen $\mathrm{K}$ : A simple, rapid, and sensitive DNA assay procedure. Anal Biochem 102: 344-352, 1980.

24. Lerch K: Monophenol monooxygenase from Neurospora crassa. Methods Enzymol 142: 165-169, 1987.

25. Kim EK, Kwon KB, Han MJ, et al: Inhibitory effect of Artemisia Capillaris extract on cytokine-induced nitric oxide formation and cytotoxicity of RINm5F cells. Int J Mol Med 19: 535-540, 2007.

26. Laemmli UK: Cleavage of structural proteins during the assembly of the head of bacteriophage T4. Nature 227: 680-685, 1970

27. Beavo JA, Rogers NL, Crofford OB, Hardman JG, Sutherland EW and Newman EV: Effects of xanthine derivatives on lipolysis and on adenosine 3 ',5'-monophosphate phosphodiesterase activity. Mol Pharmacol 6: 597-603, 1970.

28. Tamagawa T, Niki $\mathrm{H}$ and Niki A: Insulin release independent of a rise in cytosolic free $\mathrm{Ca}^{2+}$ by forskolin and phorbol ester. FEBS Lett 183: 430-432, 1985.

29. Matsuda H, Hirata N, Kawaguchi Y, et al: Melanogenesis stimulation in murine B16 melanoma cells by umberiferae plant extracts and their coumarin constituents. Biol Pharm Bull 28: 1229-1233, 2005

30. Cho YH, Kim JH, Park SM, Lee BC, Pyo HB and Park HD: New cosmetic agents for skin whitening from Angelica dahurica. J Cosmet Sci 57: 11-21, 2006.

31. Deng Y and Yang L: Effect of Angelica sinensis (Oliv.) on melanocytic proliferation, melanin synthesis and tyrosinase activity in vitro. Di Yi Jun Yi Da Xue Xue Bao 23: 239-241, 2003.

32. Eller MS and Gilchrest BA: Tanning as part of the eukaryotic SOS response. Pigment Cell Res 13 (suppl 8): 94-97, 2000.

33. Sasaki M, Horikoshi T, Uchiwa $\mathrm{H}$ and Miyachi $\mathrm{Y}$ : Upregulation of tyrosinase gene by nitric oxide in human melanocytes. Pigment Cell Res 13: 248-252, 2000.

34. Park HY, Russakovsky V, Ohno S and Gilchrest BA: The $B$ isoform of protein kinase $\mathrm{C}$ stimulates human melanogenesis by activating tyrosinase in pigment cells. J Biol Chem 268: $11742-11749,1993$.

35. Tachibana M: MITF: a stream flowing for pigment cells. Pigment Cell Res 13: 230-240, 2000.

36. Solano F, Briganti S, Picardo M and Ghanem G: Hypopigmenting agents: an updated review on biological, chemical and clinical aspects. Pigment Cell Res 19: 550-571, 2006.

37. Parvez S, Kang M, Chung HS, et al: Survey and mechanism of skin depigmenting and lightening agents. Phytother Res 20: 921-934, 2006. 